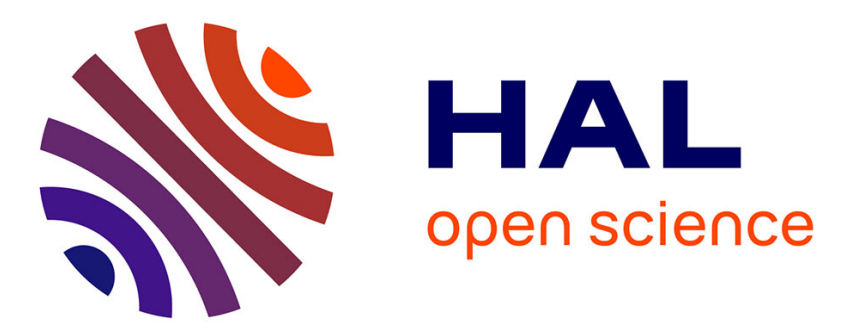

\title{
Functional Connectivity of Ventral and Dorsal Visual Streams in Posterior Cortical Atrophy
}

Raffaella Migliaccio, Cécile Gallea, Aurélie Kas, Vincent Perlbarg, Dalila Samri, Laura Trotta, Agnès Michon, Lucette Lacomblez, Bruno Dubois, Stéphane Lehericy, et al.

\section{To cite this version:}

Raffaella Migliaccio, Cécile Gallea, Aurélie Kas, Vincent Perlbarg, Dalila Samri, et al.. Functional Connectivity of Ventral and Dorsal Visual Streams in Posterior Cortical Atrophy. Journal of Alzheimer's Disease, 2016, 51 (4), pp.1119-1130. 10.3233/JAD-150934 . hal-01321378

\section{HAL Id: hal-01321378 https://hal.sorbonne-universite.fr/hal-01321378}

Submitted on 25 May 2016

HAL is a multi-disciplinary open access archive for the deposit and dissemination of scientific research documents, whether they are published or not. The documents may come from teaching and research institutions in France or abroad, or from public or private research centers.
L'archive ouverte pluridisciplinaire HAL, est destinée au dépôt et à la diffusion de documents scientifiques de niveau recherche, publiés ou non, émanant des établissements d'enseignement et de recherche français ou étrangers, des laboratoires publics ou privés. 


\section{Functional connectivity of ventral and dorsal visual streams in posterior cortical}

atrophy

R. Migliaccio, MD PhD ${ }^{\mathrm{a}, \mathrm{b}}$ C. Gallea, $\mathrm{PhD}^{\mathrm{a}, \mathrm{c}}$ A. Kas, MD PhD ${ }^{\mathrm{d}, \mathrm{e}}$ V. Perlbarg, $\mathrm{PhD}^{\mathrm{a}, \mathrm{e}, \mathrm{l}} \mathrm{D}$. Samri, Psy ${ }^{b}$ L. Trotta, MD ${ }^{\text {a,b,g }}$ A. Michon, MD ${ }^{b}$ L. Lacomblez, MD ${ }^{\text {e,h,i }}$ B. Dubois, MD ${ }^{\mathrm{a}, \mathrm{b}}$ S. Lehericy, MD PhD ${ }^{\mathrm{a}, \mathrm{c}}$ and $\mathrm{P}$. Bartolomeo MD PhD ${ }^{\mathrm{a}, \mathrm{f}}$

${ }^{\text {a} I N S E R M, ~ U 1127, ~ I n s t i t u t ~ d u ~ C e r v e a u ~ e t ~ d e ~ l a ~ M o e l l e ~ E p i n i e ̀ r e ~(I C M), ~ H o ̂ p i t a l ~ d e ~ l a ~ P i t i e ́-~}$ Salpêtrière, Paris, France; ${ }^{\mathrm{b}}$ Department of Neurology, Institut de la mémoire et de la maladie d'Alzheimer, Hôpital de la Pitié-Salpêtrière, AP-HP, Paris, France; 'Centre de Neuroimagerie de Recherche (CENIR) de l'Institut du Cerveau et de la Moelle Epiniere (ICM), Hôpital de la Pitié-Salpêtrière, Paris, France; ${ }^{\mathrm{d}}$ Service de médecine nucléaire, Hôpital PitiéSalpêtrière, APHP, Paris, France; ${ }^{\mathrm{e} I N S E R M ~ U 1146, ~ C N R S ~ U M R 7371, ~ l a b o r a t o i r e ~ d ' i m a g e r i e ~}$ biomédicale, Sorbonne université, UPMC université, Paris 60 UMCR2, Hôpital de la PitiéSalpêtrière, Paris, France; ${ }^{\mathrm{f}}$ Department of Psychology, Catholic University, Milan, Italy; ${ }^{\mathrm{g}}$ Neurology Unit, Campus Bio-Medico University, Rome, Italy; ${ }^{\mathrm{h}}$ Department des maladies du

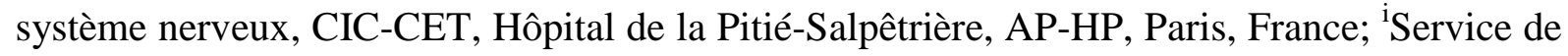
pharmacologie, Hôpital de la Pitié-Salpêtrière, AP-HP, Paris, France; 'IHU-A-ICM, Bioinformatics/Biostatistis Plateform, Paris, France.

Running title: functional connectivity in PCA.

Corresponding author: Raffaella Migliaccio, CR-ICM Brain and Spine Institute, Groupe Hospitalier Pitié-Salpêtrière, 47, boulevard de l'Hôpital, Paris, France; email: lara.migliaccio@gmail.com; telephone: +33 (0) 157274146 


\section{ABSTRACT}

Objectives: To investigate brain functional connectivity (FC) in ventral and dorsal cortical visual networks in patients with posterior cortical atrophy (PCA), the relationship between FC changes and cortical atrophy, and the association with Alzheimer's disease (AD) pathology.

Methods: Ten patients with PCA and short duration of symptoms, as well as 28 age-matched controls, participated in the study. Using resting state fMRI, we measured FC in ventral and dorsal cortical visual networks, defined on the basis of a priori knowledge of long-range white matter connections. To assess the relationships with $\mathrm{AD}$, we determined $\mathrm{AD}$ biomarkers in cerebrospinal fluid and FC in the default mode network (DMN), which is vulnerable to AD pathology. Voxel-based morphometry (VBM) analysis assessed the pattern of grey matter (GM) atrophy.

Results: PCA patients showed GM atrophy in bilateral occipital and inferior parietal regions. PCA patients had lower FC levels in a ventral network than controls, but higher FC in inferior components of the dorsal network. In particular, the increased connectivity correlated with greater GM atrophy in occipital regions. All PCA patients had positive CSF biomarkers for $\mathrm{AD}$; however, FC in global DMN did not differ from controls'.

Conclusions: FC in PCA reflects brain structure in a non-univocal way. Hyperconnectivity of dorsal networks may indicate aberrant communication in response to posterior brain atrophy or processes of neural resilience during the initial stage of brain dysfunction in PCA. The lack of difference from controls in global DMN FC highlights the atypical nature of PCA with respect to typical $\mathrm{AD}$.

Keywords: posterior cortical atrophy, functional connectivity, ventral stream, dorsal stream, brain resilience. 


\section{INTRODUCTION}

Posterior cortical atrophy (PCA) is a rare neurodegenerative dementia, often considered as an atypical variant of Alzheimer's disease (AD) $[1,2]$. Patients with PCA usually present with progressive high-level visual and visuomotor deficits, including visual agnosia, environmental disorientation, elements of Bálint's or Gerstmann's syndromes, along with praxic and language deficits [3]. Consistent with their clinical presentation, PCA patients show hypometabolism/hypoperfusion [4] and grey matter (GM) atrophy in parieto-occipital and posterior temporal cortices [5].

McMonagle et al. [3] proposed a classification of PCA into dorsal and ventral subtypes, with reference to the classic dichotomy of ventral and dorsal cortical visual streams [6]. According to current models [7], a ventral stream carries out information about perceptual features and substantiates perceptual identification. A more dorsal stream processes instead information about object locations, and mediates the visual control of skilled actions. PCA patients may present with "ventral" deficits such as pure alexia [8], or with "dorsal" deficits such as optic ataxia or visuo-spatial neglect [9-11]. However, overlapping clinical presentations are very often observed [12].

Anatomically, occipital and anterior temporal regions linked by the inferior longitudinal fasciculus (ILF) represent a main component of the ventral stream [13]. The dorsal stream corresponds to inferior and superior parietal brain regions connected with the frontal lobes by a long-range white matter (WM) bundle, the superior longitudinal fasciculus (SLF)[13]. Migliaccio et al. [9] investigated the GM and WM correlates of the neuropsychological profile in a group of patients with PCA, who showed either predominantly ventral or additional dorsal cognitive deficits. The combined results of voxel- 
based morphometry (VBM) (for GM) and DTI-tractography (for WM) suggested that selective visuo-perceptual and visuo-spatial deficits typical of PCA do not result from cortical damage alone, but by a network-level dysfunction including WM damage along the major visual pathways $[9,10]$. However, functional interactions within ventral and dorsal networks in PCA remain unknown.

In this study, for the first time, we explored functional connectivity (FC) between brain areas along ventral and dorsal networks, on the basis of observations emphasizing that FC reflects the brain structural organization [14]. Because PCA is frequently associated with AD pathology, we determined AD biomarkers in cerebrospinal fluid (CSF), and explored FC in the default mode network (DMN), which is highly vulnerable to deposition of amyloid- $\beta$ $[15]$.

We hypothesized that ventral and dorsal functional networks should be altered in PCA proportionally to posterior atrophy, with consequent loss of efficiency in information exchange. Moreover, because PCA is considered a variant of early age of onset AD, differences in global DMN FC between PCA patients and controls might occur, similar to typical AD. Parietal and posterior temporal regions, usually atrophic in PCA, are comprised in the DMN (Migliaccio 2009; Ossenkoppele et al, Human Brain Mapping, 2015).

\section{METHODS}

\subsection{Subjects}

Ten PCA patients and 28 age-matched healthy subjects without history of neurological or psychiatric disease participated in the study (Table 1). Clinical and cognitive data were acquired at the Centre National de Référence 'Démences Rares', located at the "Institut de la memoire et de la maladie d'Alzheimer" (IM2A), in the Pitié-Salpêtrière Hospital, Paris. 
Clinical diagnosis was based on a multi-disciplinary evaluation including clinical history and neurological examination, caregiver interview, and a neuropsychological test battery. Medical records of patients clinically diagnosed with PCA were reviewed by two neurologists (RM and LT) to ensure they met PCA diagnostic criteria. Following criteria proposed by McMonagle [3], and modified by Alladi [16] were applied: 1) presentation with progressive visual or visuospatial impairment in the absence of ophthalmologic impairment; 2) evidence of complex visual disorder on examination: elements of Balint's (and Gerstmann's) syndrome, visual agnosia, dressing apraxia, or environmental disorientation; 3) proportionately less memory loss. To meet criteria, patients were required to present with early complaints of visual and visuospatial impairment in the absence of memory complaints. Subjects with early episodic memory impairment, ophthalmologic disease, extrapyramidal symptoms or signs, hallucinations, cognitive fluctuations, or substantial MRI T2 white matter hyperintensities in the occipito-parietal regions were not included in this study.

All patients underwent a neuropsychological screening battery. Patients also underwent a detailed exploration of "posterior" brain functions, through a battery specifically conceived for PCA patients, and exploring all the cognitive functions arising from occipitotemporal and occipito-parieto-frontal circuits. Neuropsychological assessment was performed by an experienced neuropsychologist blind to the MRI results, and included global cognitive assessment with Mini Mental State Examination (MMSE)[17], the Frontal Assessment Battery (FAB)[18], and the Clinical Dementia Rating (CDR) scale [19]. General memory, language and executive tests were also performed, such as the Free and Cued Selective Reminding Test [20] or Rey Auditory Verbal Learning Test (Rey AVLT) [21], word generation tasks for category and letter fluency [22], as well as visual and verbal direct and backward span [23]. Limb apraxia was evaluated clinically by assessing ideomotor apraxia on verbal instruction as well as gesture imitation. Evaluation of visual and visuospatial deficits 
included the "Cookie Theft" picture from the Boston Diagnostic Aphasia Examination [24], or the five series of overlapping figures [25] to assess simultanagnosia, and confrontation naming to assess visual agnosia $[24,26]$ in which the patient has to name a series of images shown by the examiner. Signs of Balint's and Gerstmann's syndromes were assessed as detailed in Kas et al. [4]. Briefly, assessment included evaluation of oculomotor apraxia (defined as the inability to voluntarily direct one's gaze to a particular point), optic ataxia (impaired goal-directed hand movements towards visually presented targets), right-left distinction, finger agnosia, acalculia, and agraphia. Alexia was assessed by asking the patient to read six lines of text; errors and time spent were noted. Visual neglect was assessed by using standardized visuo-spatial tests such as line bisection, bells cancellation and copy of drawing [27]. Clinically, visual agnosia and alexia were considered as "ventral" deficits, whereas elements of Balint's and Gerstmann's syndromes, visual neglect, and ideomotor apraxia were considered as resulting from more "dorsal" deficits.

Moreover, all PCA patients had a lumbar puncture to search for AD biomarkers, with quantification of total tau (hereafter tau), phosphorylated tau at threonine 181 (P-tau) and amyloid- $\beta$ peptide 1-42 (A $\beta 1-42$ ) (for procedure see [28]). Diagnosis of AD was made on the basis of current biological criteria based on CSF analyses. In the present study, A $\beta 1-42$ and tau (T-tau or P-tau) are used in combination, and the CSF AD signature, which combines low A $\beta 1-42$ and high T-tau or P-tau concentrations, significantly increases the accuracy of AD diagnosis (Dubois et al, Lancet Neurol 2014). Ratios are also considered. With respect to biomarker values predictive of $\mathrm{AD}$, a previous study of our department has provided two main cut-offs, namely a P-tau/A $\beta 1-42$ cut-off of $<0.211 \mathrm{pg} / \mathrm{ml}$ and a tau/A $\beta 1-42$ cut-off of $<1.23 \mathrm{pg} / \mathrm{ml}$ (Cruz de Souza et al., 2011; see also for a recent application Teichmann et al, Brain 2014). These cut-offs had respective sensitivities of $91.7 \%$ and $95 \%$, and respective specificities of $89.1 \%$ and $84.8 \%$ in distinguishing $\mathrm{AD}$ from other neurodegenerative 
dementias. Moreover, the ratio of tau/A $\beta 1-42$ was the best biomarker to differentiate $A D$ from frontotemporal lobar degeneration, and showed a specificity of $96.6 \%$ in a series of patients with diagnostic confirmation either by genetics or by post-mortem examination (e.g. Bian et al., Neurology 2008). The study was approved by the local committee on human research. All subjects provided written informed consent before participating.

\subsection{Imaging Protocol}

The MR protocol was carried out with a 3T whole-body system (Siemens, Erlangen, Germany) at the Center for Magnetic Resonance Research (CENIR), Brain and Spine Institute (ICM), Paris. The functional images were acquired by $\mathrm{T} 2 *$-weighted fast echo planar imaging (flip angle $=90^{\circ}$, echo time $=30 \mathrm{~ms}$, repetition time $=2.26 \mathrm{~s}$ ) from 45 interleaved axial slices $\left(\right.$ gap $=0.3 \mathrm{~mm}$ ) with a $3 \times 3 \times 3 \mathrm{~mm}^{3}$ voxel size for the resting state. The resting-state fMRI experiment consisted of one 8-minute run in which participants were asked to relax with their eyes closed, without falling asleep. Each run consisted of 200 EPI volumes. A high-resolution structural volume was also acquired using a T1-weighted 3D magnetization prepared rapid gradient echo (MP-RAGE) sequence (160 sagittal images; thickness $1 \mathrm{~mm}$; FOV $256 \times 256$ $\mathrm{mm}^{2}$; matrix size $\left.256 \times 256\right)$.

\subsection{Structural and functional MRI analysis}

2.3.1 VBM study was performed using SPM8 and the Diffeomorphic Anatomical Registration Exponentiated Lie Algebra (DARTEL) registration method [29]. Briefly, (i) T1weighted images were segmented [30] to produce GM, WM and CSF probability maps in the Montreal Neurological Institute (MNI) space; (ii) tissue segmentations were averaged across participants and smoothed with an $8 \mathrm{~mm}$ full-width at half-maximum (FWHM) Gaussian kernel to create customised prior probability maps; (iii) original T1-weighted images were 
segmented a second time using the custom priors to obtain new segmentation and normalization parameters; (iv) T1-weighted images were rigidly aligned (using the rigid-body component of the normalization parameters from step [iii]), segmented into GM and WM (using the segmentation parameters from step [iii]) and resampled to $1.5 \mathrm{~mm}$ isotropic voxels; (v) GM segments were imported in DARTEL and coregistered; (vi) the DARTEL template was created and the obtained flow fields were applied to the rigidly-aligned segments to warp them to the common DARTEL space and then modulated using the Jacobian determinants. Since the DARTEL process warps to a common space that is smaller than the MNI space, the modulated images from DARTEL were normalised to the MNI template using an affine transformation estimated from the DARTEL GM template and the a priori GM probability map without re-sampling (http://brainmap.wisc.edu/normalizeDARTELtoMontreal Neurological Institute). Finally, images were smoothed with a 8 -mm full-width at halfmaximum Gaussian kernel. GM maps were compared between patients and controls using an ANOVA model in Statistical Parametric Mapping (SPM8), adjusting for subject's age, gender, and total intracranial volume. A significance threshold of $\mathrm{p}<0.05$ corrected for multiple comparisons (Family Wise Error [FWE]) was adopted. Given that our PCA patients had relatively short disease duration, and thus showed less atrophy than more advanced patients, we also calculated VBM results at an uncorrected threshold $(\mathrm{p}<0.001)$.

The values of atrophy to be used for statistical correlations was obtained by subtracting from 1 the mean smoothed Jacobian-modulated gray matter and white matter estimates (corrected for total intracranial volume), for each atrophic regions (occipital, parietal, posterior temporal).

\subsubsection{Resting state fMRI study}

Pre-processing 
K-space functional data were first processed to reduce physiological noise using a retrospective estimation of respiration and heart beat [31]. Then, statistical parametric mapping (SPM) 8 software was used to correct for subject's motion, reduce low-frequency drift of the signal (high-pass filter with cutoff frequency $4.16 \times 10^{-3} \mathrm{~Hz}$ ) and smooth the images with an isotropic spatial Gaussian filter $(\mathrm{FWHM}=5 \mathrm{~mm})$

\section{Regions of interest selection}

We aimed at exploring the status of the functional connectivity within the dorsal and ventral visual networks, by using a priori knowledge of long-range white matter (WM) connections. The dorsal network was parceled by following the three main branches of the superior longitudinal fasciculus (superior, SLF I; middle, SLF II; inferior, SLF III) [32]. The ventral network was defined by the anatomical trajectory of the inferior longitudinal fasciculus (ILF)[33]. The definition of ventral and dorsal ROIs, belonging to the networks, was based on previous anatomical tractography studies [33, 34]. Cortical regions of interest (ROI) were obtained automatically by using the PickAtlas SPM8 toolbox [35]. Figure 1 shows all the seed regions. All the networks were separately explored in the left and in the right hemisphere.

More specifically, the dorsal network included: i) a superior component comprising the superior parietal lobule and precuneus (Brodmann area, BA, 5 and 7) and superior medial and lateral frontal regions (BA 8, 9, 32); ii) a middle component, comprising the angular and supramarginal gyri (BA 39 and 40), along with superior and lateral frontal regions partially overlapping with the superior component (BA 8, 9); iii) an inferior component, comprising the supramarginal gyrus (BA 40), and lateral middle and inferior frontal regions (BA 44, 45 and 47).

The ventral network included the occipital lobe (BA 17, 18, and 19) and the anterior temporal pole (BA 38). 
We also explored FC within the DMN. DMN included the following brain regions: precuneus, posterior cingulate, inferior parietal lobules, and medial frontal areas including the anterior cingulate cortex, bilaterally [36].

\section{Data analysis and Statistics}

To quantify the between- and within-network connectivity, we used a measure derived from entropy, hierarchical integration, which is aimed at quantifying information exchanges between areas constituting the networks [37]. Hierarchical integration is particularly adapted to the global estimation of FC at the network level. We hereafter refer to hierarchical integration as FC (see [38-43] for recent applications). The value of hierarchical integration, for each network, was used for group comparison (PCA patients vs. controls). To do so, the values of integration were inferred by using a Bayesian numerical sampling scheme $(5,000$ samples) that approximated the posterior distribution of the parameters of interest in a group analysis [38]. In that framework, we tested that the posterior probability $\mathrm{p}(A \mid \mathbf{y})$ of the assertion $A$ that "patients have lower between-networks integration than healthy controls" related to any pair of networks (dorsal-superior, middle and inferior- and ventral). The validity of the assertion could be tested using evidence $e(A \mid \mathbf{y})$, measured in decibels $(\mathrm{dB})$, equal to the ratio of the probability that $A$ to be true to the probability that $A$ to be false, in a base 10 logarithmic scale [44]. According to this measure, two values of integration will be considered as significantly different when $|e(A \mid \mathbf{y})|>10 \mathrm{~dB}$, that is to say that the probability of A being true is 10 times higher than the probability of A being false. A significant positive value of evidence shows that the assertion $A$ is true, whereas a significant negative value shows that the complementary assertion $\bar{A}$ has to be considered as true. 
We assessed the relationship between connectivity values in altered network and cortical atrophy (occipital, parietal, posterior temporal regions) by calculating Spearman correlation coefficients for small samples.

\section{RESULTS}

\subsection{Cognitive and biological profile}

Patients demonstrated a mild-to-moderate global cognitive impairment on the tests assessing the global cognitive status, such as MMSE, FAB and CDR (Table 1). Working memory was also impaired in both the verbal and the visuospatial modalities. Conversely, phonemic and categorical fluency were in the normal range. The most frequent "dorsal" deficits were spatial neglect (100\%), ideomotor apraxia (90\%), and acalculia (80\%), simultanagnosia (70\%), and optic ataxia (70\%). Concerning "ventral" deficits, visual agnosia was present in $70 \%$ of patients (Table 1). Supplementary table 1 also reports the starting clinical picture for each PCA patient. All PCA patients had a CSF biomarkers profile compatible with AD pathology (Table 1).

\subsection{Structural and functional MRI results}

\subsubsection{VBM results}

In PCA patients, compared to healthy subjects, VBM demonstrated GM atrophy centered on bilateral occipital, parietal and posterior temporal regions, with right-side predominance (figure 2 and table 2) (all p<0.05, FWE). Lowering the threshold disclosed smaller areas of atrophy in the frontal regions and cingulate cortex (table 2) $(\mathrm{p}<0.001)$. 


\subsubsection{Resting state fMRI results}

In their dorsal networks, PCA patients showed a bilateral increase of FC in the inferior components $(0.98<\mathrm{p}<1)$ (figure 1$)$. The bilateral middle component showed a tendency towards a slight increase of FC in patients compared to controls $(0.76<\mathrm{p}<0.84)$. Finally, there was no group difference in the bilateral superior component $(0.74<\mathrm{p}<0.76)$.

Conversely, FC decreased bilaterally between the occipital areas and the temporal areas (ventral network) in PCA patients compared to controls $(\mathrm{p}=0.98)$.

No differences emerged in global DMN FC between PCA patients and controls $(\mathrm{p}=0.54)$.

In the right hemisphere, the amount of grey matter of the occipital cortex negatively correlated with FC in the inferior dorsal component ( $\mathrm{Rho}=-0.83, \mathrm{p}=0.0056)$ (supplementary figure 1). In a few words, the greater the occipital atrophy, the higher the FC in the inferior component of dorsal network. We have not found correlations between other brain areas and functional networks. 


\section{Discussion}

We assessed functional connectivity in ventral and dorsal functional networks in a well-characterized group of patients with PCA and positive AD biomarkers, on the basis of anatomical knowledge of the normal architecture of these networks. Atrophy occurred in bilateral occipital, posterior temporal and inferior parietal cortices, with right-side predominance. FC demonstrated an expected reduction in ventral occipital-temporal pathways. In contrast, the inferior component of the dorsal network demonstrated a bilateral increase of FC levels, which was less pronounced or absent in the middle and superior components. In the most severely affected right hemisphere, higher FC in the inferior component of the dorsal networks correlated with the amount of GM atrophy in the occipital cortex. Finally, global DMN FC did not differ between PCA patients and controls.

The present study shows for the first time the occurrence of FC bi-directional changes in ventral and dorsal visual networks, in PCA. The present findings support the general hypothesis that clinical deficits in PCA result from dysfunctions in large-scale networks, as previously demonstrated in other neurodegenerative dementias [45]. In this vein, exploring the white matter, we suggested that the clinical features in PCA might not result from cortical atrophy alone but by damage along dorsal and ventral visual pathways in particular in the right hemisphere $[9,10,46]$. Here, we showed that FC was reduced in ventral networks with severe occipital atrophy, as expected. The possible physiological basis of increased connectivity in the inferior components of the dorsal networks, and its correlation with occipital atrophy will be specifically discussed.

Parieto-frontal networks, anatomically connected by the SLF III (inferior dorsal component), are important for attentional mechanisms, including vigilant and sustained attention [47, 48], especially in the right hemisphere. All PCA patients included in our study 
showed signs of visual neglect, which affected the left hemispace in nine out of ten cases. Dysfunction of the inferior component of the dorsal networks in the right hemisphere is a crucial mechanism of visual neglect, and can even contribute to right-sided neglect in neurodegenerative patients $[49,50]$. In the present series, however, left-sided neglect was much more frequent than right-sided neglect, consistent with evidence from other studies of neglect in neurodegeneration [51]. In this framework and because our patients had relatively short disease duration, increased FC in this network could be considered as an early signature of PCA. Recent fMRI studies on typical AD [52] or mild cognitive impairment [53] suggest that states of functional hyperconnectivity, which can later progress to hypoconnectivity, may indicate an early phase of brain dysfunction. Increased FC can also occur in psychiatric conditions such as schizophrenia [54]: disease-induced impaired connectivity may lead to isolation of some brain systems, which can then demonstrate increased FC because they become less susceptible to influence from other systems [54].

Alternatively, the paradoxical increase of FC may reflect the engagement of compensatory mechanisms at the initial stages of PCA. This might be a general mechanism in the early phases of several neurodegenerative diseases, and in particular in focal variants. For example, DMN connectivity in patients with early-onset $\mathrm{AD}$ was increased in the anterior temporal areas, and positively correlated with memory performance [55]. The finding of elevated connectivity in the dorsal component is also consistent with previous studies showing differences in anterior (hyperconnected) vs. posterior (hypoconnected) networks in AD [56]. Taken together, this evidence possibly indicates a resilience mechanism in parietofrontal network, as a response to reduced connectivity in more ventral network. Resilience to neuropathological damage corresponds to the ability to optimize performance through effective recruitment of brain networks [57]. As long as the inferior parietal cortex is sufficiently preserved at the structural level at the early stage of the disease, it may ensure 
information processing and transmission to the prefrontal cortex. More generally, parietofrontal systems in particular might play a role of "brain/cognitive reserve", and delay cognitive impairment in neurodegenerative diseases, perhaps through the activity of noradrenergic circuits [58]. Thus, partially preserved brain regions (such as the inferior parietal lobule) could try to compensate for neuronal and functional degradation. Some example of the resilience neuronal has been reported in the literature of PCA. A patient with preserved numerical skills demonstrated increased fMRI activation in temporal structures during numerical processing [59]. Unfortunately, given the small number of subjects in the present study and the lack of homogeneous cognitive scores, we cannot to calculate correlations with neuroimaging in order to verify this hypothesis.

We also found a negative correlation between the degree of occipital atrophy and the higher FC level in the inferior component of the right dorsal component. Severe atrophy in the right occipital lobe seems to influence particularly this inferior parieto-frontal network, which would explain its hyperconnectivity state. This correlation can be explained supposing the presence of elective connections between these regions. The presence of structural connections between specific visual areas (e. g. V6) and intraparietal regions has been demonstrated on awake macaque monkeys, by injecting neuronal tracers. These reciprocal connections play a pivotal role in the dorsal visual stream, by distributing the visual information coming from the occipital lobe to parietal cortex [60]. The presence of human homologue of V6 has been showed [61], and resting-state MRI functional connectivity studies in humans have shown strong functional connectivity between parietal and visual areas (included human homologue of V6) [62].

Our results are in agreement with a very recent study [63], exploring the default mode network (DMN), as well as different non-DMN networks, in distinctive phenotypes of AD, 
included PCA. Consistent with our data, PCA patients had impaired connectivity in nonDMN, termed "higher visual network" (broadly corresponding to our ventral network). Unfortunately, the authors did not study any dorsal component [63]. Very importantly, and in agreement with our data, the authors did not find difference in DMN [63]. All together these results highlight the atypical nature of PCA as compared to AD [1] in term of disease onset and perhaps progression. Finally and very interestingly, the same authors found that patients affected by another focal variant of $\mathrm{AD}$ (so called logopenic aphasia) showed higher connectivity in the anterior subcomponent of DMN, compared with controls. To explain the increase of FC in logopenic patients, these authors have also evoked a compensatory mechanism [63].

The main limitations of the present study are the relatively small number of PCA patients included and the lack of correlation with neuropsychological scores. Another limitation is the absence of typical AD patients as control group for DMN FC analyses. However, since many previous studies have investigated FC changes in $\mathrm{AD}$, we do not consider this as a major shortcoming.

In conclusion, we have demonstrated that FC reflects the brain structure in a nonunivocal/bi-directional way. PCA patients showed a paradoxical hyperconnectivity of attention-related dorsal networks, either as a result of early network dysfunction or as a sign of attempt of compensation in response to occipital atrophy early in the course of the disease. Parieto-frontal regions thus constitute crucial nodes of networks vulnerable to AD pathology in PCA patients, consistent with the neuronal vulnerability hypothesis of neurodegenerative diseases [45]. At variance with typical AD, where the disease progression mainly occurs within the DMN, in PCA it rather implicates ventral and dorsal cortical visual streams.

\section{Acknowledgements}


Raffaella Migliaccio is supported by the "France Alzheimer" and "Philippe Chatrier" Foundations. Paolo Bartolomeo gratefully acknowledges the support of an AP-HP translational research grant. Cecile Gallea was supported by IHU-A-ICM ('Investissement d'avenir' program, ANR-10-IAIHU-06). 


\section{References}

[1] Migliaccio R, Agosta F, Rascovsky K, Karydas A, Bonasera S, Rabinovici GD, Miller BL, Gorno-Tempini ML (2009) Clinical syndromes associated with posterior atrophy: early age at onset AD spectrum. Neurology 73, 1571-1578.

[2] Migliaccio R, Agosta F, Possin KL, Rabinovici GD, Miller BL, Gorno-Tempini ML (2012) White matter atrophy in Alzheimer's disease variants. Alzheimers Dement 8, S78-87 e71-72.

[3] McMonagle P, Deering F, Berliner Y, Kertesz A (2006) The cognitive profile of posterior cortical atrophy. Neurology 66, 331-338.

[4] Kas A, de Souza LC, Samri D, Bartolomeo P, Lacomblez L, Kalafat M, Migliaccio R, Thiebaut de Schotten M, Cohen L, Dubois B, Habert MO, Sarazin M (2011) Neural correlates of cognitive impairment in posterior cortical atrophy. Brain 134, 14641478.

[5] Whitwell JL, Jack CR, Jr., Kantarci K, Weigand SD, Boeve BF, Knopman DS, Drubach DA, Tang-Wai DF, Petersen RC, Josephs KA (2007) Imaging correlates of posterior cortical atrophy. Neurobiol Aging 28, 1051-1061.

[6] Ungerleider L, Mishkin, M (1982) Two Cortical Visual Systems, in D.J. Ingle, M.A. Goodale, R.J.W. Mansfield (Eds.), Analysis of motor behavior Cambridge MIT Press, Cambridge, MA, pp. 549-586.

[7] Goodale MA, Milner AD (1992) Separate visual pathways for perception and action. Trends Neurosci 15, 20-25.

[8] Mendez MF, Cherrier MM (1998) The evolution of alexia and simultanagnosia in posterior cortical atrophy. Neuropsychiatry Neuropsychol Behav Neurol 11, 76-82.

[9] Migliaccio R, Agosta F, Scola E, Magnani G, Cappa SF, Pagani E, Canu E, Comi G, Falini A, Gorno-Tempini ML, Bartolomeo P, Filippi M (2012) Ventral and dorsal visual streams in posterior cortical atrophy: a DT MRI study. Neurobiol Aging 33, 2572-2584.

[10] Migliaccio R, Agosta F, Toba MN, Samri D, Corlier F, de Souza LC, Chupin M, Sharman M, Gorno-Tempini ML, Dubois B, Filippi M, Bartolomeo P (2012) Brain networks in posterior cortical atrophy: a single case tractography study and literature review. Cortex 48, 1298-1309.

[11] Lehmann M, Barnes J, Ridgway GR, Wattam-Bell J, Warrington EK, Fox NC, Crutch SJ (2011) Basic visual function and cortical thickness patterns in posterior cortical atrophy. Cereb Cortex 21, 2122-2132.

[12] Videaud H, Torny F, Prado-Jean A, Couratier P (2008) Use of the Visual Object and Space Perception (VOSP) test battery in two cases of posterior cortical atrophy. Neurocase 15, 32-36.

[13] ffytche DH, Blom JD, Catani M (2010) Disorders of visual perception. J Neurol Neurosurg Psychiatry 81, 1280-1287.

[14] Greicius MD, Supekar K, Menon V, Dougherty RF (2009) Resting-state functional connectivity reflects structural connectivity in the default mode network. Cereb Cortex 19, 72-78.

[15] Greicius MD, Srivastava G, Reiss AL, Menon V (2004) Default-mode network activity distinguishes Alzheimer's disease from healthy aging: evidence from functional MRI. Proc Natl Acad Sci U S A 101, 4637-4642.

[16] Alladi S, Xuereb J, Bak T, Nestor P, Knibb J, Patterson K, Hodges JR (2007) Focal cortical presentations of Alzheimer's disease. Brain 130, 2636-2645. 
[17] Folstein MF, Folstein SE, McHugh PR (1975) "Mini-mental state". A practical method for grading the cognitive state of patients for the clinician. $J$ Psychiatr Res 12, 189-198.

[18] Dubois B, Slachevsky A, Litvan I, Pillon B (2000) The FAB: a Frontal Assessment Battery at bedside. Neurology 55, 1621-1626.

[19] Morris JC (1997) Clinical dementia rating: a reliable and valid diagnostic and staging measure for dementia of the Alzheimer type. Int Psychogeriatr 9 Suppl 1, 173-176; discussion 177-178.

[20] Grober E, Buschke, H (1987) Genuine memory deficits in dementia. Dev Neuropsychol, 3, 13-36.

[21] Rey A (1958) L'examen clinique an psychologie, Presses universitaires de France, Paris.

[22] Kremin H, Perrier, D, De Wilde, M (1999) DENO-100-Paradigme expérimental et test clinique de dénomination contrôlée: effet relatif de 7 variables expérimentales sur les performances de 16 sujets atteints de maladies dégénératives. . Rev Neuropsychol $\mathbf{9}$, 439-440.

[23] Wechsler D (1981) The Wechsler Adult Intelligence Scale-Revised. , San Antonio: Psychological Corporation.

[24] Goodglass H, Kaplan, E (1983) The assessment of aphasia and related disorders. Philadelphia, PA: Lea \& Febige.

[25] Gainotti G, D'Erme P, Bartolomeo P (1991) Early orientation of attention toward the half space ipsilateral to the lesion in patients with unilateral brain damage. $J$ Neurol Neurosurg Psychiatry 54, 1082-1089.

[26] Deloche GaH, D. (1997) Test de denomination orale d'images, Paris.

[27] Azouvi P, Samuel C, Louis-Dreyfus A, Bernati T, Bartolomeo P, Beis JM, Chokron S, Leclercq M, Marchal F, Martin Y, De Montety G, Olivier S, Perennou D, Pradat-Diehl P, Prairial C, Rode G, Sieroff E, Wiart L, Rousseaux M (2002) Sensitivity of clinical and behavioural tests of spatial neglect after right hemisphere stroke. J Neurol Neurosurg Psychiatry 73, 160-166.

[28] Teichmann M, Kas A, Boutet C, Ferrieux S, Nogues M, Samri D, Rogan C, Dormont D, Dubois B, Migliaccio R (2013) Deciphering logopenic primary progressive aphasia: a clinical, imaging and biomarker investigation. Brain 136, 3474-3488.

[29] Ashburner J (2007) A fast diffeomorphic image registration algorithm. Neuroimage 38, 95-113.

[30] Ashburner J, Friston KJ (2005) Unified segmentation. Neuroimage 26, 839-851.

[31] Hu X, Le TH, Parrish T, Erhard P (1995) Retrospective estimation and correction of physiological fluctuation in functional MRI. Magn Reson Med 34, 201-212.

[32] Thiebaut de Schotten M, Dell'Acqua F, Forkel SJ, Simmons A, Vergani F, Murphy DG, Catani M (2011) A lateralized brain network for visuospatial attention. Nat Neurosci 14, 1245-1246.

[33] Catani M, Thiebaut de Schotten M (2008) A diffusion tensor imaging tractography atlas for virtual in vivo dissections. Cortex 44, 1105-1132.

[34] Thiebaut de Schotten M, Ffytche DH, Bizzi A, Dell'Acqua F, Allin M, Walshe M, Murray R, Williams SC, Murphy DG, Catani M (2011) Atlasing location, asymmetry and inter-subject variability of white matter tracts in the human brain with MR diffusion tractography. Neuroimage 54, 49-59.

[35] Tzourio-Mazoyer N, Landeau B, Papathanassiou D, Crivello F, Etard O, Delcroix N, Mazoyer B, Joliot M (2002) Automated anatomical labeling of activations in SPM using a macroscopic anatomical parcellation of the MNI MRI single-subject brain. Neuroimage 15, 273-289. 
[36] Greicius MD, Krasnow B, Reiss AL, Menon V (2003) Functional connectivity in the resting brain: a network analysis of the default mode hypothesis. Proc Natl Acad Sci U $S$ A 100, 253-258.

[37] Marrelec G, Bellec P, Krainik A, Duffau H, Pelegrini-Issac M, Lehericy S, Benali H, Doyon J (2008) Regions, systems, and the brain: hierarchical measures of functional integration in fMRI. Med Image Anal 12, 484-496.

[38] Marrelec G, Bellec P, Benali H (2006) Exploring large-scale brain networks in functional MRI. J Physiol Paris 100, 171-181.

[39] Marrelec G, Krainik A, Duffau H, Pelegrini-Issac M, Lehericy S, Doyon J, Benali H (2006) Partial correlation for functional brain interactivity investigation in functional MRI. Neuroimage 32, 228-237.

[40] Coynel A, Blanc G, Marache A, Schafer J, Dabrin A, Maneux E, Bossy C, Masson M, Lavaux G (2009) Assessment of metal contamination in a small mining- and smeltingaffected watershed: high resolution monitoring coupled with spatial analysis by GIS. $J$ Environ Monit 11, 962-976.

[41] Boly M, Perlbarg V, Marrelec G, Schabus M, Laureys S, Doyon J, Pelegrini-Issac M, Maquet P, Benali H (2012) Hierarchical clustering of brain activity during human nonrapid eye movement sleep. Proc Natl Acad Sci U S A 109, 5856-5861.

[42] Marcotte K, Perlbarg V, Marrelec G, Benali H, Ansaldo AI (2013) Default-mode network functional connectivity in aphasia: therapy-induced neuroplasticity. Brain Lang 124, 45-55.

[43] Ghazi Saidi L, Perlbarg V, Marrelec G, Pelegrini-Issac M, Benali H, Ansaldo AI (2013) Functional connectivity changes in second language vocabulary learning. Brain Lang 124, 56-65.

[44] Jaynes E (2003) Vol. I - Principles and Elementary Applications. In Probability Theory: The Logic of Science. Cambridge University Press, Cambridge.

[45] Seeley WW, Crawford RK, Zhou J, Miller BL, Greicius MD (2009) Neurodegenerative diseases target large-scale human brain networks. Neuron 62, 4252.

[46] Caso F, Agosta F, Mattavelli D, Migliaccio R, Canu E, Magnani G, Marcone A, Copetti M, Falautano M, Comi G, Falini A, Filippi M (2015) White Matter Degeneration in Atypical Alzheimer Disease. Radiology, 142766.

[47] Bartolomeo P (2014) Attention disorders after right brain damage: Living in halved worlds. , London: Springer-Verlag.

[48] Robertson I, \& Garavan, H. (2004) Vigilant Attention. In In: MS Gazzaniga, editor. The Cognitive Neurosciences, 3rd edition MIT Press, pp. 563-578.

[49] Bartolomeo P, Dalla Barba G, Boisse MF, Bachoud-Levi AC, Degos JD, Boller F (1998) Right-side neglect in Alzheimer's disease. Neurology 51, 1207-1209.

[50] Andrade K, Samri D, Sarazin M, de Souza LC, Cohen L, Thiebaut de Schotten M, Dubois B, Bartolomeo P (2010) Visual neglect in posterior cortical atrophy. BMC Neurol 10, 68.

[51] Silveri MC, Ciccarelli N, Cappa A (2011) Unilateral spatial neglect in degenerative brain pathology. Neuropsychology 25, 554-566.

[52] Damoiseaux JS, Prater KE, Miller BL, Greicius MD (2012) Functional connectivity tracks clinical deterioration in Alzheimer's disease. Neurobiol Aging 33, 828 e819830.

[53] Bai F, Watson DR, Shi Y, Wang Y, Yue C, YuhuanTeng, Wu D, Yuan Y, Zhang Z (2011) Specifically progressive deficits of brain functional marker in amnestic type mild cognitive impairment. PLoS One 6, e24271. 
[54] van den Heuvel MP, Sporns O, Collin G, Scheewe T, Mandl RC, Cahn W, Goni J, Hulshoff Pol HE, Kahn RS (2013) Abnormal rich club organization and functional brain dynamics in schizophrenia. JAMA Psychiatry 70, 783-792.

[55] Gour N, Felician O, Didic M, Koric L, Gueriot C, Chanoine V, Confort-Gouny S, Guye M, Ceccaldi M, Ranjeva JP (2013) Functional connectivity changes differ in early and late-onset alzheimer's disease. Hum Brain Mapp.

[56] Zhou J, Greicius MD, Gennatas ED, Growdon ME, Jang JY, Rabinovici GD, Kramer JH, Weiner M, Miller BL, Seeley WW (2010) Divergent network connectivity changes in behavioural variant frontotemporal dementia and Alzheimer's disease. Brain 133, 1352-1367.

[57] Steffener J, Stern Y (2012) Exploring the neural basis of cognitive reserve in aging. Biochim Biophys Acta 1822, 467-473.

[58] Robertson IH (2013) A right hemisphere role in cognitive reserve. Neurobiol Aging.

[59] Delazer M, Benke T, Trieb T, Schocke M, Ischebeck A (2006) Isolated numerical skills in posterior cortical atrophy--an fMRI study. Neuropsychologia 44, 1909-1913.

[60] Galletti C, Gamberini M, Kutz DF, Fattori P, Luppino G, Matelli M (2001) The cortical connections of area V6: an occipito-parietal network processing visual information. Eur J Neurosci 13, 1572-1588.

[61] Pitzalis S, Galletti C, Huang RS, Patria F, Committeri G, Galati G, Fattori P, Sereno MI (2006) Wide-field retinotopy defines human cortical visual area v6. J Neurosci 26, 7962-7973.

[62] Kravitz DJ1, Saleem KS, Baker CI, Mishkin M (2011). A new neural framework for visuospatial processing. Nat Rev Neurosci 12, 217-230.

[63] Lehmann M, Madison C, Ghosh PM, Miller ZA, Greicius MD, Kramer JH, Coppola G, Miller BL, Jagust WJ, Gorno-Tempini ML, Seeley WW, Rabinovici GD (2015) Loss of functional connectivity is greater outside the default mode network in nonfamilial early-onset Alzheimer's disease variants. Neurobiol Aging 36, 2678-2686. 
Tables

Table 1. Demographic, clinical and cognitive characteristics of patients with posterior cortical atrophy and healthy controls.

\begin{tabular}{|c|c|c|}
\hline & PCA (=10) & Controls (=28) \\
\hline Age & $61(4)$ & $57(9)$ \\
\hline Gender $(\mathbf{W} / \mathbf{M})$ & $8 / 2$ & $16 / 12$ \\
\hline Handedness & $10 \mathrm{R}$ & $28 \mathrm{R}$ \\
\hline CSF AD biomarkers & 10 & \\
\hline Disease Duration & $3.2(0.9)$ & \\
\hline Clinical Dementia Rating (CDR) scale & $1.2(0.7)$ & \\
\hline \multicolumn{2}{|l|}{ Global cognitive assessment (mean and SD) } & \\
\hline $\operatorname{MMSE}(\geq 27)$ & $17.5(5)^{*}$ & \\
\hline $\mathrm{FAB}(\geq 16)$ & $10(2.7)^{*}$ & \\
\hline Verbal span backwards $(\geq 6)$ & $2.6(1.2)^{*}$ & \\
\hline Spatial span backwards $(\geq 6)$ & $1.4(1.1)^{*}$ & \\
\hline Phonemic fluency $(\geq 15)$ & $13.1(9.3)$ & \\
\hline Category fluency $(\geq 15)$ & $9.3(7.3)$ & \\
\hline \multicolumn{2}{|l|}{ Parietal/Dorsal symptoms (\% of impaired patients) } & \\
\hline \multicolumn{2}{|l|}{ Balint Syndrome } & \\
\hline Optic ataxia & $70 \%$ & \\
\hline Simultagnosia & $70 \%$ & \\
\hline \multicolumn{2}{|l|}{ Gerstmann syndrome } & \\
\hline Agraphia & $60 \%$ & \\
\hline Acalculia & $80 \%$ & \\
\hline Finger agnosia & $70 \%$ & \\
\hline Right-left disorientation & $40 \%$ & \\
\hline Visual neglect & $100 \%$ & \\
\hline Ideomotor apraxia & $90 \%$ & \\
\hline \multicolumn{2}{|c|}{ Ventral/occipito-temporal symptoms (\% of impaired patients) } & \\
\hline Visual agnosia & $70 \%$ & \\
\hline Alexia & $50 \%$ & \\
\hline
\end{tabular}

* Scores 1 SD below the normal threshold.

Abbreviations: $\mathrm{CSF}=$ cerebrospinal fluid; $\mathrm{FAB}$ : frontal assessment battery; $\mathrm{M}=$ man; $\mathrm{MMSE}=$ mini-mental state examination, $\mathrm{SD}=$ standard deviation; $\mathrm{W}=$ woman. 
Table 2. Grey matter (GM) areas showing atrophy in posterior cortical atrophy patients compared with healthy controls $(\mathrm{p}<0.05$ Family Wise Error). For some areas, results at $\mathrm{p}<0.001$ uncorrected are reported.

\begin{tabular}{|c|c|c|}
\hline GM anatomical region $(\mathrm{BA})$ & $\begin{array}{c}\text { MNI } \\
\text { Coordinates } \\
(\mathbf{x}, \mathbf{y}, \mathbf{z})\end{array}$ & T value \\
\hline Superior occipital gyrus $(18,19)$ & $\begin{array}{l}\text { R } 28,-78,20 \\
\text { L }-16,-96,18\end{array}$ & $\begin{array}{c}5.12 \\
3.85^{*}\end{array}$ \\
\hline Middle occipital gyrus (19) & $\begin{array}{l}\mathrm{R} 40,-72,2 \\
\mathrm{~L}-28,-72,22\end{array}$ & $\begin{array}{l}5.10 \\
6.90\end{array}$ \\
\hline Fusiform gyrus (37) & $\begin{array}{l}\text { R } 30,-72,-10 \\
\text { L }-28,-66,-10\end{array}$ & $\begin{array}{l}4.74 \\
4.24 *\end{array}$ \\
\hline Superior parietal gyrus $(5,7)$ & $\begin{array}{l}\text { R } 18,-50,54 \\
\text { L }-16,-72,48\end{array}$ & $\begin{array}{l}3.42 * \\
3.53 *\end{array}$ \\
\hline Inferior parietal lobule $(39,40)$ & $\begin{array}{l}\text { R } 36,-46,40 \\
\text { L }-32,-46,40\end{array}$ & $\begin{array}{l}5.15 \\
4.10^{*}\end{array}$ \\
\hline $\begin{array}{l}\text { Posterior cingulate cortex/precuneus } \\
(23,7)\end{array}$ & $\begin{array}{r}\mathrm{R} 4,-20,42 \\
2,-52,44 \\
\mathrm{~L}-2,-20,42 \\
\end{array}$ & $\begin{array}{l}4.37 * \\
3.52 *\end{array}$ \\
\hline Posterior middle temporal gyrus (39) & $\begin{array}{l}\text { R } 50,-44,10 \\
\text { L }-48,-62,-2\end{array}$ & $\begin{array}{l}4.75 \\
4.87 \\
\end{array}$ \\
\hline $\begin{array}{l}\text { Posterior inferior temporal gyrus ( } 37, \\
22)\end{array}$ & $\begin{array}{l}\text { R } 42,-64,-6 \\
\text { L }-48,-62,-5 \\
\end{array}$ & $\begin{array}{r}6.44 \\
4.82 * \\
\end{array}$ \\
\hline Middle frontal gyrus (48) & $\mathrm{R} 42,10,22$ & $4.11^{*}$ \\
\hline Superior frontal gyrus (6) & $L-26,-2,64$ & $3.7 *$ \\
\hline
\end{tabular}

$* \mathrm{p}<0.001$ uncorrected.

Abbreviations: $\mathrm{GM}=$ grey matter; $\mathrm{BA}=$ Brodmann area; $\mathrm{MNI}=$ Montreal Neurological Institute. 
Supplementary table 1. Clinical picture and AD biological status for each PCA patient.

\begin{tabular}{|c|c|c|c|c|c|c|c|c|c|c|}
\hline Patient & $\# 1$ & $\# 2$ & \#3 & $\# 4$ & \#5 & $\# 6$ & \#7 & $\# 8$ & $\# 9$ & $\# 10$ \\
\hline Gender & W & $\mathrm{M}$ & W & W & W & W & W & W & W & $\mathrm{M}$ \\
\hline Age (years) & 59 & 62 & 60 & 69 & 59 & 63 & 68 & 59 & 54 & 64 \\
\hline $\begin{array}{c}\text { Disease } \\
\text { duration } \\
\text { (years) }\end{array}$ & 4 & 4 & 4 & 3 & 4 & 3 & 3 & 3 & 3 & 1 \\
\hline MMSE (/30) & 21 & 21 & 14 & 10 & 17 & 21 & 21 & 12 & 13 & 25 \\
\hline FAB (/18) & 10 & 13 & 5 & 8 & 10 & 11 & 14 & 12 & 7 & 10 \\
\hline CDR & 0.5 & 0.5 & 1 & 2 & 2 & 1 & 1 & 2 & 2 & 0.5 \\
\hline $\begin{array}{c}\text { First } \\
\text { Symptom } \\
\text { reported } \\
\end{array}$ & $\begin{array}{c}\text { Left } \\
\text { neglect }\end{array}$ & $\begin{array}{c}\text { Left } \\
\text { neglect } \\
\text { and } \\
\text { simultagn } \\
\text { osia } \\
\end{array}$ & $\begin{array}{l}\text { Visual and } \\
\text { visuospati } \\
\text { al deficits }\end{array}$ & $\begin{array}{l}\text { Simultagno } \\
\text { sia and } \\
\text { Gerstmann }\end{array}$ & $\begin{array}{c}\text { Alexia and } \\
\text { agraphia }\end{array}$ & $\begin{array}{c}\text { Simultagno } \\
\text { sia and } \\
\text { Gerstmann }\end{array}$ & $\begin{array}{c}\text { Visual } \\
\text { agnosia }\end{array}$ & $\begin{array}{l}\text { Visual and } \\
\text { visuospati } \\
\text { al deficits }\end{array}$ & $\begin{array}{c}\text { Acalculia, } \\
\text { alexia, and } \\
\text { agraphia }\end{array}$ & $\begin{array}{c}\text { Visual } \\
\text { agnosia }\end{array}$ \\
\hline \multicolumn{11}{|c|}{ Cognitive evaluation } \\
\hline $\begin{array}{l}\text { Verbal span } \\
\text { backwards }\end{array}$ & 2 & 2 & 3 & 3 & 2 & 4 & 4 & 3 & 0 & 3 \\
\hline $\begin{array}{l}\text { Spatial span } \\
\text { backwards }\end{array}$ & 2 & 2 & 0 & 2 & 0 & 1 & 0 & 3 & 2 & 2 \\
\hline $\begin{array}{l}\text { Phonemic } \\
\text { fluency }\end{array}$ & 25 & 20 & 3 & 6 & 4 & 11 & 20 & 18 & 0 & 24 \\
\hline $\begin{array}{l}\text { Category } \\
\text { Fluency }\end{array}$ & 17 & 17 & 5 & 1 & 10 & 22 & 8 & 4 & 0 & 9 \\
\hline \multicolumn{11}{|c|}{ Parietal/Dorsal symptoms } \\
\hline \multicolumn{11}{|c|}{ Balint's Syndrome } \\
\hline Optic ataxia & + & + & + & - & + & + & + & - & + & - \\
\hline $\begin{array}{l}\text { Optic ataxia } \\
\text { score }(/ 8)\end{array}$ & 4 & 5 & 4 & 8 & 4 & 4 & 4 & 8 & 4 & 8 \\
\hline $\begin{array}{l}\text { Simultagno } \\
\text { sia }\end{array}$ & + & + & + & + & - & + & - & + & + & - \\
\hline $\begin{array}{l}\text { Overlapping } \\
\text { Figures } \\
\text { (/20) }\end{array}$ & 16 & 13 & - & - & 19 & - & - & 16 & 13 & 0 \\
\hline \multicolumn{11}{|c|}{ Gerstmann's Syndrome } \\
\hline Agraphia & + & - & + & + & + & + & - & + & + & - \\
\hline Acalculia & - & + & + & + & + & + & + & + & + & - \\
\hline $\begin{array}{l}\text { Finger } \\
\text { agnosia }\end{array}$ & - & + & + & + & + & - & + & + & + & - \\
\hline $\begin{array}{l}\text { Right-left } \\
\text { disorientati } \\
\text { on }\end{array}$ & - & - & + & - & - & + & - & + & + & - \\
\hline $\begin{array}{l}\text { Ideomotor } \\
\text { apraxia }\end{array}$ & + & + & + & + & + & + & + & - & + & + \\
\hline $\begin{array}{l}\text { Hemineglec } \\
\mathrm{t}\end{array}$ & + & + & + & + & + & + & + & + & + & + \\
\hline \multicolumn{11}{|c|}{ Ventral/occipito-temporal symptoms } \\
\hline $\begin{array}{l}\text { Visual } \\
\text { agnosia }\end{array}$ & - & + & + & + & + & + & - & + & - & + \\
\hline Alexia & - & + & - & - & + & - & + & + & + & + \\
\hline
\end{tabular}




\begin{tabular}{|c|c|c|c|c|c|c|c|c|c|c|}
\hline \multicolumn{11}{|c|}{ AD CSF biomarkers } \\
\hline $\begin{array}{c}A \beta-42 \\
(>500)\end{array}$ & 263 & 217 & 246 & 318 & 209 & 395 & 318 & 334 & 219 & 354 \\
\hline T-tau $(<450)$ & 388 & 328 & 336 & 1183 & 421 & 545 & 1200 & 721 & 489 & 1026 \\
\hline P-tau $(<60)$ & 62 & 50 & 67 & 143 & 68 & 79 & 158 & 139 & 70 & 84 \\
\hline IATI $(>1)$ & 0.4 & 0.35 & 0.39 & 0.2 & 0.3 & 0.45 & 0.19 & 0.31 & 0.27 & 0.24 \\
\hline $\begin{array}{c}\text { tau/b42 } \\
(<1.23)\end{array}$ & 1.48 & 1.51 & 1.37 & 3.72 & 2.01 & 1.38 & 3.77 & 2.16 & 2.23 & 2.90 \\
\hline $\begin{array}{c}p-\operatorname{tau} / \mathrm{b} 42 \\
(<0.211)\end{array}$ & 0.24 & 0.23 & 0.27 & 0.45 & 0.325 & 0.20 & 0.50 & 0.42 & 0.32 & 0.24 \\
\hline
\end{tabular}


Figure captions
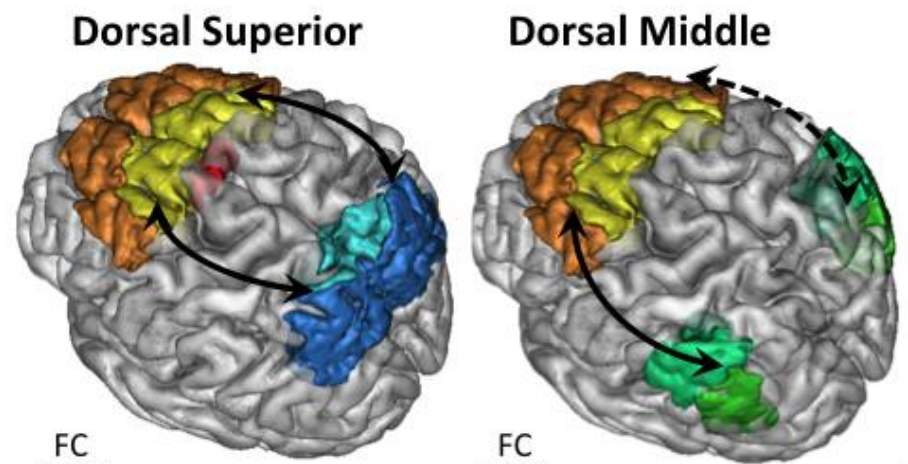

Dorsal Inferior
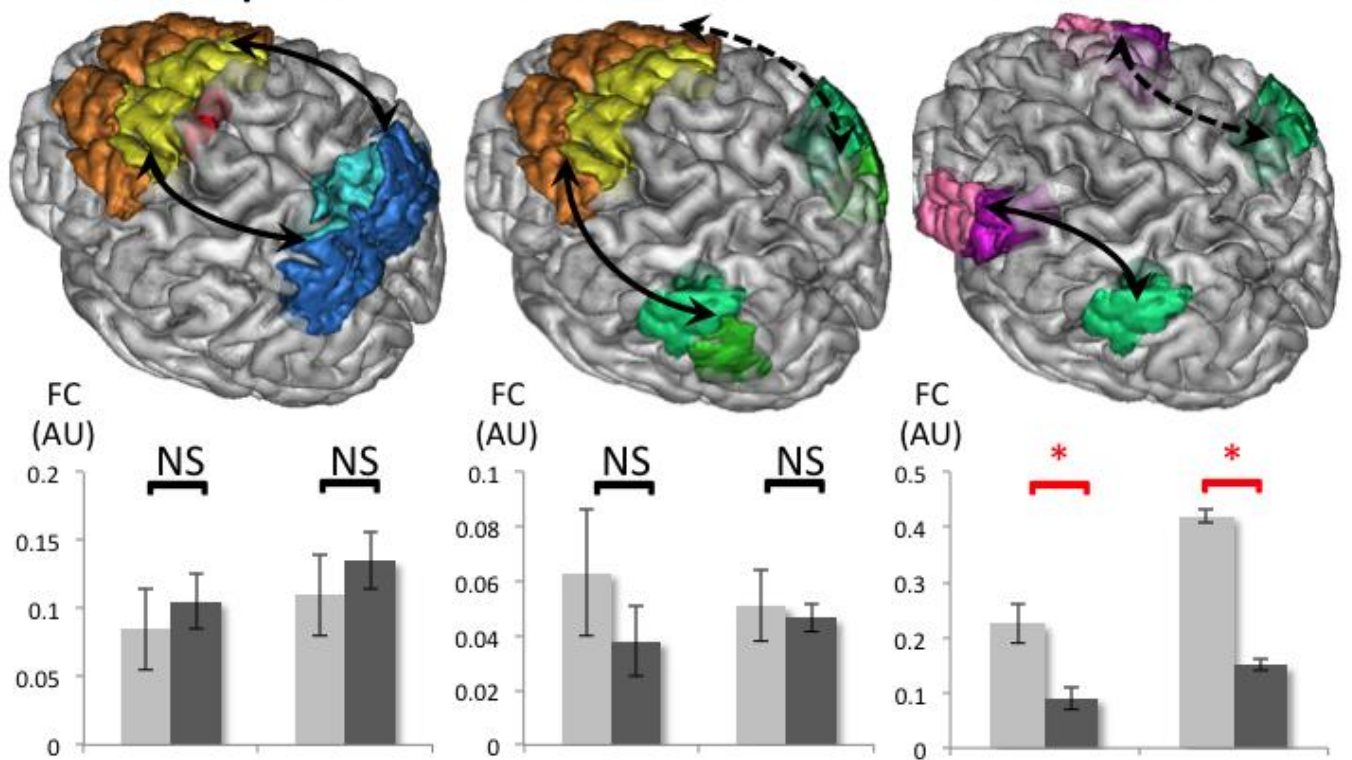

$\mathrm{LH}$

$\mathrm{LH}$

$\mathrm{RH}$

LH

$\mathrm{RH}$

Ventral

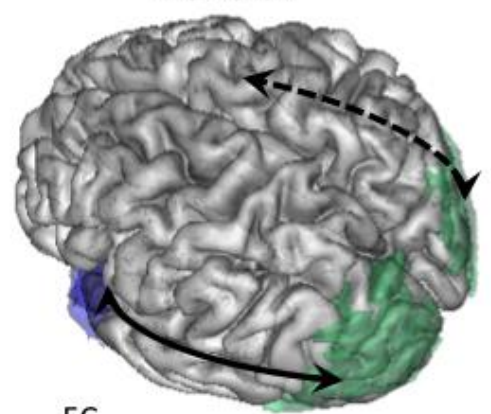

Default Mode Network
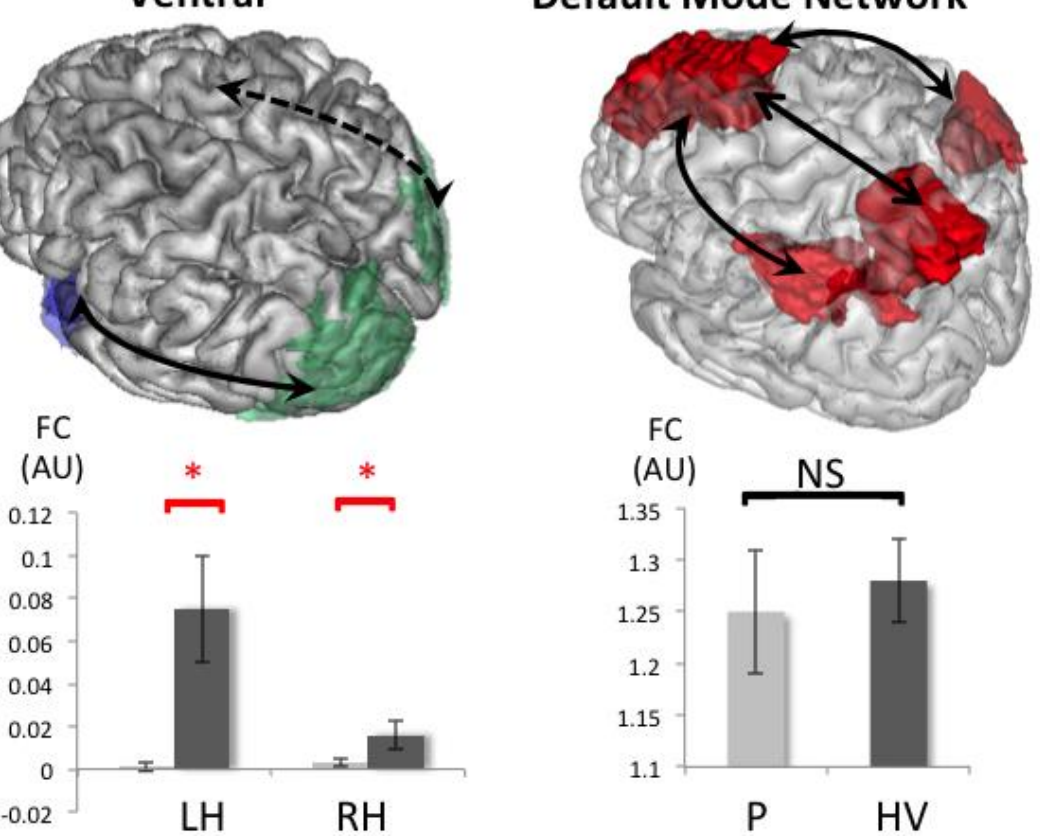

Figure 1. Seed regions for the superior, middle and inferior components of dorsal networks, as well as for the ventral network, and default mode network. The arrows represent measures of functional connectivity (FC) in the networks. For the dorsal network: the superior component showed no group difference, bilaterally $(0.74<\mathrm{p}<0.76)$; the middle component showed a non-significant trend towards an FC increase in patients compared to controls 
$(0.76<\mathrm{p}<0.84)$, bilaterally; finally, in the inferior component, patients' FC increased significantly compared to controls $(0.98<\mathrm{p}<1)$, bilaterally. The ventral network showed decreased FC in patients $v s$. controls $(\mathrm{p}=0.98)$, bilaterally. There were no significant differences in the default mode network (DMN) $(\mathrm{p}=0.54)$.

$\mathrm{FC}=$ functional connectivity, $\mathrm{AU}=$ arbitrary units, $\mathrm{LH}=$ left hemisphere, $\mathrm{RH}=$ right hemisphere, $\mathrm{P}=$ patients, $\mathrm{HV}=$ healthy volunteers, $\mathrm{NS}=$ not significant, $*=$ significant difference in terms of Bayesian statistics (see methods). 

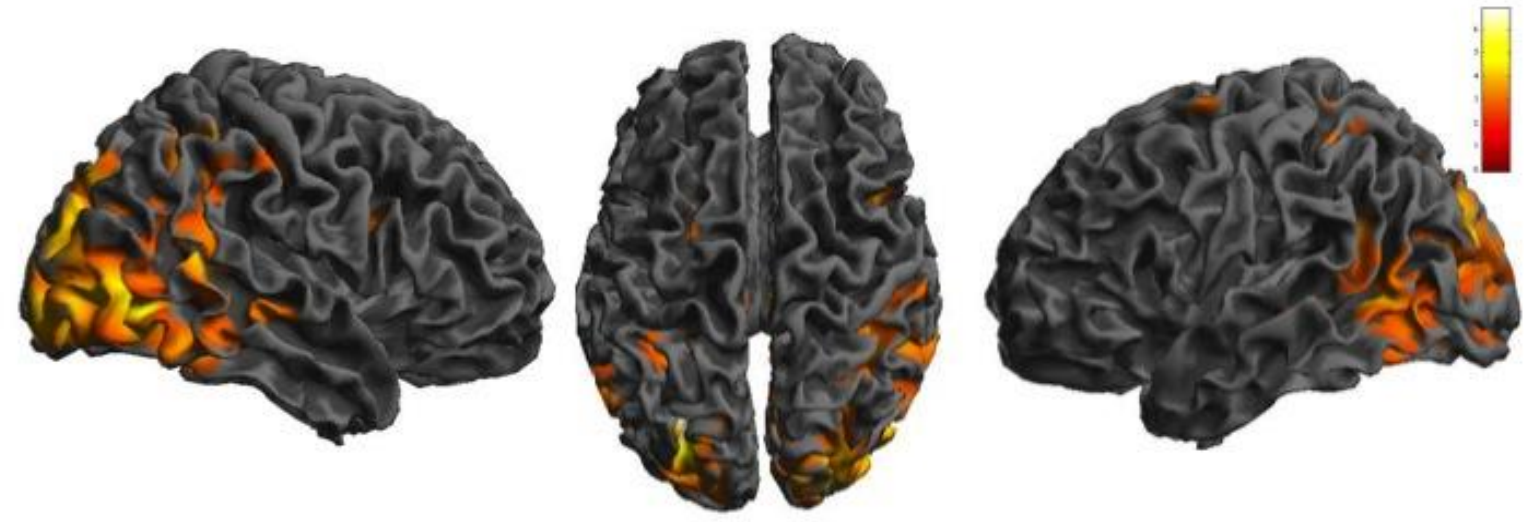

Figure 2. VBM results for PCA patients compared to controls. Regions of gray matter atrophy are shown on the 3-dimensional rendering of the Montreal Neurological Institute standard brain. For display purpose, results are shown at a threshold of $\mathrm{p}<0.001$ uncorrected. 


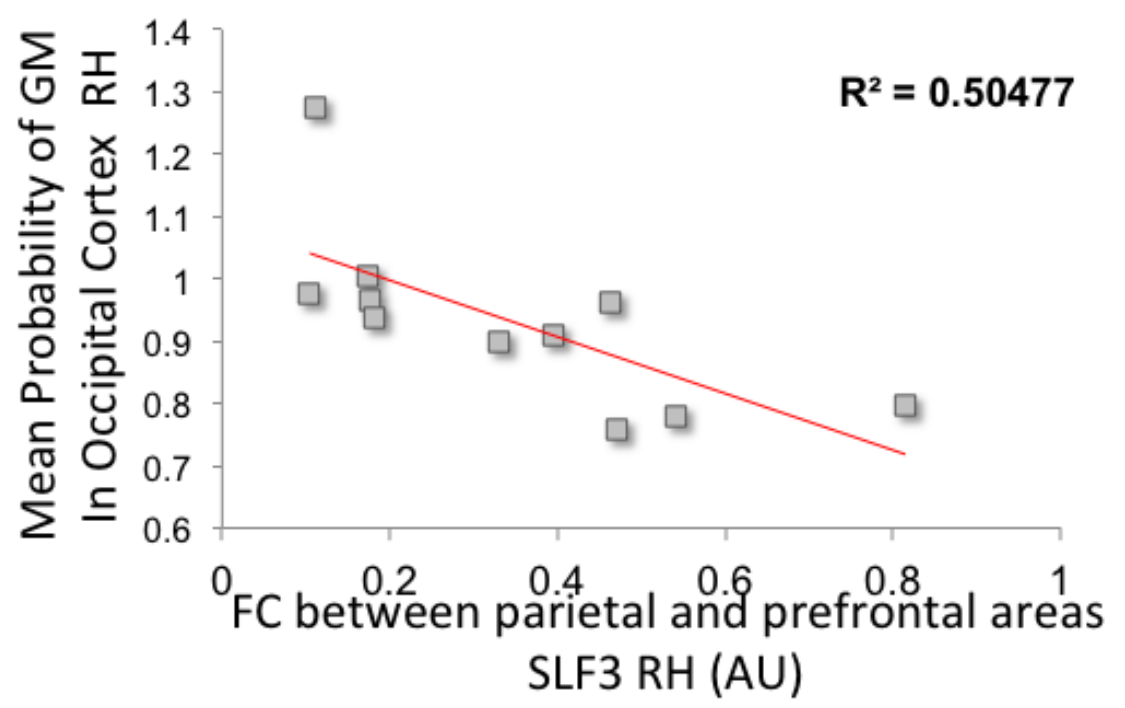

Supplementary fig. 1 Correlation between functional connectivity in right inferior component of dorsal network (SLF) and amount of grey matter atrophy in right occipital cortex $($ Rho $=-0.83, \mathrm{p}=0.0056)($ Pearson coefficient $)$.

$\mathrm{FC}=$ functional connectivity, $\mathrm{AU}=$ arbitrary units, $\mathrm{RH}=$ right hemisphere. 